\title{
GUERRA E PAZ EM NORBERT EUAS
}

Ana Luisa Fayet Sallas ${ }^{1}$

\section{RESUMO}

Neste ensaio desenvolvo uma reflexão sobre a temática da guerra e da paz e os processos civilizadores em Norbert Elias em três aspectos: a) algumas considerações acerca do conceito de guerra e de paz - de Kant a Bobbio; b) relaciono estes conceitos aos termos presentes na obra de Norbert Elias; e finalmente pretendo apontar para o alcance da proposta teórica de Elias na análise da questão da violência no Brasil. Trata-se, em suma, de articular uma discussão teórica das relações entre processos micros e macrossociológicos, fundados em grande medida pela constância de processos "civilizadores" e "des-civilizadores" presentes ao longo do tempo em nossas sociedades, esboçando um quadro explicativo para esse processo.

PALAVRAS-ChAVE: Guerra. Paz. Processos civilizadores. Processos descivilizadores.

\begin{abstract}
In this essay I develop a reflection on the theme of war and peace and the civilizing processes in Norbert Elias in three aspects : a) some considerations about the concept of war and peace - from Kant to Bobbio ; b) I relate these concepts to the terms present in the work of Norbert Elias; and c) I intend to finally point to the scope of the theoretical proposal of Elias in analyzing the issue of violence in Brazil. It is, in short, to articulate a theoretical discussion of the relation between micro and macrosociological processes, founded largely by the constancy of the "civilizing" and "de-civilizing" processes, present over time in our societies, outlining an explanatory framework for this process.
\end{abstract}

KEYWORDS: War. Peace. Civilizing processes. De-civilizing processes.

Gostaria na minha apresentação abordar a temática da guerra e da paz em Norbert Elias basicamente em três aspectos: no primeiro, tecer algumas considerações acerca do conceito de guerra e de paz, no segundo, relacionar esse conceitos aos termos presentes na obra de Norbert Elias. Finalmente pretendo apontar para o alcance da proposta teórica de Elias, análise da questão do estado de guerra não declarado em que vivemos hoje em nosso país, esboçando um quadro explicativo para esse processo.

Quando falamos em paz, a tendência é a de considerá-la frequentemente

1 Professora Doutora do departamento de Sociologia da Universidade Federal do Paraná e do Programa de Pós-graduação em Sociologia da UFPR. analuisa@ufpr.br 
como um estado de espírito, como uma emoção ou sentimento interior, que o indivíduo alcança. Por outro lado, pensamos a paz como algo que pudesse se traduzir apenas em seu aspecto exterior e, portanto, relacional. Assim, temos, de um lado, o indivíduo em paz consigo mesmo e, de outro, a exterioridade a ela associada. Exterioridade como relação quando temos a sua definição geral expressa pela assertiva de que a paz é, segundo Bernard Manin:

a relação isenta de conflitos que seres humanos ou coletividades mantêm entre si. Surge como a conciliação de dois elementos: a diversidade das entidades a que se refere e a ausência de violência. O primeiro meio de conjugar estes dois aspectos é a ordem, mediante a qual cada elemento vem ocupar o lugar que lhe compete. Se cada um tiver o seu lugar próprio, distinto do lugar dos outros, ninguém procurará violentar quem quer que seja, com a condição que se aceite esse lugar e nele permaneça (MANIN, 1985, p. 274).

Essa expressão é uma ideia de Santo Agostinho a respeito da paz. Daí para frente, podemos sintetizar aqui todo o movimento de reflexões dos filósofos, desde Platão, passando por Kant e mesmo Marx que ao destaca: sendo os homens e as coisas diferentes por Natureza, isto é, desiguais, diferentes serão também os respectivos papéis e estatutos sociais, e a ordem será hierárquica. Assim, Marx afirmou que o direito burguês é abstrato porque considera indivíduos como iguais, o que na realidade não ocorre "porque não seriam diferente se não fossem desiguais". Só uma hierarquia pode conseguir a síntese entre a desigualdade dos homens e a unidade da cidade, isto é, a paz; mas com a condição indispensável de que essa desigualdade seja adequada à sua natureza" (in Manin, 1985, p. 274)

Numa outra direção, podemos pensar também na instituição da pax romana - única paz duradoura conhecida no mundo antigo, era a paz imposta por uma potência imperial dentro dos limites nos quais se estendera seu próprio domínio, que permaneceu como uma paz interna confrontada ao mundo exterior considerado bárbaro. O papado na Alta Idade Média soube impor seu poder pela apropriação, mediante a corrente de pensamento chamada agostinismo político, do projeto de paz universal. Esse projeto serviu de fundamento e justificação teórica do poder do papa. A noção de paz universal pôde surgir porque a manutenção e a estabilidade de uma ordem deixaram de parecer ligadas à exterioridade dos povos nas suas relações recíprocas. Com isso, foi possível constituir um ponto de vista universal sobre os homens, acessível a um único homem - o papa.

Mas, a ideia da paz como ordem universal vai ser progressivamente 
destruída devido a dois fatores: a transferência progressiva da função pacificadora para as várias potências soberanas e as guerras religiosas que acentuaram a aspiração dos povos à paz e que foram concluídas pelo poder civil - apesar de a Igreja Católica Romana não abdicar de suas pretensões universalistas.

Esses tipos de acordos marcaram o malogro de uma ideia de paz conseguida por meio de uma ordem única, dando origem a um novo conceito, em que pese a sua fragilidade, de que a paz pode também significar a coexistência de ordens diferentes, além de afirmarem conjuntamente dois princípios essenciais: o primado da política e a possibilidade de uma existência cotidiana fundada no respeito mútuo. Esses princípios contribuem para fazer nascer a ideia de que, ao lado da paz de uma ordem universal, sem dúvida impossível, permanece uma paz baseada na tolerância e na diversidade. Desse modo, podemos afirmar que o malogro da paz fundada na instituição de uma hierarquia universal deixa o campo livre a novos princípios sobre os quais se vai construir uma outra ideia de paz: a coexistência e a tolerância entre entidades diferentes, mas com direitos iguais, o concurso das vontades nos conselhos e nos congresso, enfim, o princípio do equilíbrio de forças.

$\mathrm{Na}$ ordem política, o significado dessa ideia de paz esteve associado a todas as reflexões que apontavam para o instauração da paz pelo concurso de vontades soberanas. Aliás, é esse mesmo princípio presente nas organizações internacionais como as Organizações das Nações Unidas. Essas ideias estavam expressas em Hobbes ao abrir a perspectiva que supera a ideia da guerra como uma ordem natural, para pensar que a paz só pode ser assegurada por uma instância simultaneamente interior e exterior à comunidade. Para se sair do estado primordial da humanidade de guerra de todos contra todos, segundo a hipótese hobbesiana, a solução racional não poderia ser outra senão a da paz de todos com todos. A instituição da paz civil é para ele uma forma de contrato: os súditos cedem os seus direitos a um outro, o qual não toma parte ativa no contrato. O pacto entre indivíduos institui, pois, um elemento exterior em relação aos cidadãos. O soberano está, desse modo, na Cidade, pois, graças a ele, os súditos se unificaram numa só entidade moral. Assim, estão estabelecidos os laços que vinculam a paz e a exterioridade.

A busca da paz levaria também os homens a darem vida `aquelas comunidades parciais que são os Estados nos quais o titular do direito usa a espada, isto é, a força coativa de poder impedir no interior de sua própria esfera o 
surgimento de guerras privadas. Mas os soberanos podem continuar a viver nas suas relações recíprocas no estado de natureza e, portanto, num estado perene de guerras $^{2}$. O que para Elias será resultante do que denominou de o Processo Civilizador - pacificação interna e sanções às formas de violências não legítimas e, ao mesmo tempo, o enaltecimento externo das virtudes guerreiras dos povos levados às guerras. Mas retomaremos adiante essa questão.

Com Kant, que em 1795 publica sob a forma de um tratado universal o livro Pela Paz Perpétua, temos em aberto a possibilidade não efetiva da paz, mas a ideia do alcance moral do dever de manter a paz - e de torná-la perpétua. A instância simultaneamente interior e exterior à comunidade é aquela formada pelos Estados. A exterioridade é necessária à soberania. O soberano congrega a sociedade numa unidade encarnada na sua pessoa. Não Ihes dita apenas as leis, mas também a institui como sociedade. Segundo Kant, o povo não existe enquanto tal senão pela sua submissão a um soberano. Para que o soberano possa aparecer ao mesmo tempo como exterior à comunidade e como fazendo parte dela, nada melhor do que uma situação privilegiada: a guerra. Mas para Kant, era essencial uma forma de governo na qual o povo pudesse controlar as decisões do soberano de modo a tornar impossíveis as guerras como ato arbitrário do príncipe ou, nas suas palavras:

Se é requerida a anuência dos cidadãos para decidir se a guerra deve ou não ser realizada, nada mais natural do que pensar que, tendo de fazer recair sobre si todas as calamidades da guerra, eles refletirão durante muito tempo antes de iniciar um jogo tão ruim"(in BOBBIO, 2000, p. 527).

Por outro lado, para que as nações alcançassem o progresso era necessária a existência da paz, especialmente naquela instância que proporcionaria justamente esta finalidade: o mercado é assim estabelecido como uma nova ficção, para além dos Deuses e dos próprios homens. O recurso a essa ficção justifica-se ao lembrarmos que, num mundo sem transcendência em que as pessoas são iguais e as vontades diferentes, só uma instância exterior pode oferecer a garantia de paz. $\mathrm{O}$ mercado seria, então, outra faceta da exterioridade na qual se alicerça o fundamento da paz. Centro imaginário que produz efeitos reais e eficazes, porque transfere para as coisas, para fora da influência dos homens, o fundamento último da sociedade.

É um dado indiscutível que os homens desejam a paz, e que não fazem a

2 Segundo Bobbio, Norberto. Teoria Geral da Política: a filosofia política e as lições dos clássicos. Editora Campus : Rio de Janeiro, 2000, pg. 526. 
guerra simplesmente pela guerra. Como Aristóteles já havia observado: parece, pois, que a felicidade consiste nos ócios e no descanso, e não fazemos a guerra senão para vivermos em paz. Embora pareça banal, esta proposição aristotélica tem um decisivo alcance: a paz definida como a tranquilidade obtida pela autossuficiência aparenta-se à felicidade da qual ela constitui um elemento. É natural os homens desejarem ser felizes. Todos também desejam a paz. Nenhuma política de poder, por mais desenfreada que seja, pode anular esse fato, mesmo que para tão almejado fim sejam arrastados em constantes guerras.

A paz é um objetivo sempre pretendido e sempre desejado por si mesmo. Se os homens conscientemente a procuram, só podem concebê-la como paz perpétua, ainda que esta se revele efêmera. A paz perpétua, portanto, não designa uma ideia ou uma condição entre muitas outras, mas se define como objetivo da vontade humana.

Num outro extremo, para caracterizar a guerra como forma de solucionar conflitos, Norberto Bobbio observa que não basta fazer referência ao uso da força entendida como violência lícita e autorizada (lícita porque autorizada). A guerra é sempre, em primeiro lugar, uma força exercida coletivamente: é um exercício de força disciplinado por regras e tem o objetivo de resolver uma controvérsia com a razão das armas. Em segundo lugar, a guerra é caracterizada por uma violência contínua. Trata-se de uma forma de violência coletiva, não acidental, que pressupõe uma forma de organização, um aparato predisposto e adestrado ao objetivo da guerra (2000, p. 516).

É refletindo sobre a temática da guerra que em seu livro "A Condição Humana", Elias retoma um dos temas centrais de sua obra - a questão da violência e os meios de a controlar. Estas reflexões de Elias foram traçadas na ocasião da celebração do $40^{\circ}$ aniversário do fim da Segunda Grande Guerra Mundial. As suas considerações sobre a guerra como expressão mais brutal das relações de violência inserem-se na perspectiva incorporada até os nossos dias da "condição humana", a guerra constitui o último reduto de relações entre povos marcados pela imposição bruta da força. Segundo Elias, a evolução da humanidade vai ser marcada pelo controle das pulsões instaurando se mecanismos sociais de regulação pacífica dos conflitos - o que denominou justamente de o processo civilizador. Constata, no entanto, que ao lado desse processo que visa à pacificação crescente das sociedades humanas, ocorrem processos "descivilizadores" ainda de forma 
recorrente.

Elias constata que, de um lado, mediante o desenvolvimento científico e tecnológico, os homens conseguiram instaurar uma vivência relativamente pacificada em face de ataques externos. Por outro lado, a atitude dos homens em relação a sua vida em comum, em sociedade de diversos níveis, é ainda muito determinada por imagens de desejos e medos, por ideias e contra ideias, por representações mítico-mágicas. Ainda hoje, vemos uma guerra em nome de mitos coletivos ou, em nome de ideologias sociais - a da Democracia Americana $X$ Fundamentalismo do Islã -, como forma de se justificar o valor incomparável da própria nação.

Elias assinala que as nações são movidas muitas vezes por uma embriaguez hegemônica, que em uma situação determinada se pode propagar a vastas camadas de um povo, alimentados por fantasias coletivas, segundo as quais o povo a que se pertence e, assim, o próprio indivíduo estão destinados à grandeza, o que significa, habitualmente, a dominação de todos os outros povos a sua volta, seja por ordem divina, seja pela história ou pela matança.

O que acontece também é que todos os homens transportam consigo, no seus habitus pessoais, as particularidades dos habitus do seu grupo, e que o destino de cada homem singular é determinado igualmente pelo destino e pela reputação dos grupos a que ele ou ela pertence. Esse aspecto foi muito bem demonstrando em várias obras de Elias, como na "Sociedade de Corte" e em "Os Estabelecidos e Outsiders".

Se os Estados hegemônicos da atualidade, e os Estados com maior poder militar, seguirem a tradição milenar da humanidade, segundo a qual é evidente que grupos humanos rivais podem lutar pela sua segurança e, se possível, pela própria posição de supremacia entre os demais grupos humanos recorrendo para tanto a violência física, há uma luta de vida e de morte, estarão a abandonar, com toda probabilidade, não só grande parte da sua própria população, mas também uma parte considerável da humanidade a uma morte mais o menos cruel.

A poderosa coação exercida por essa tradição milenar da humanidade no sentido da solução dos conflitos e entre os grupos pela força das armas, a fraca medida em que os dirigentes dos Estados mais importantes são capazes de se libertar da pressão dessa tradição, da pressão das instituições e dos hábitos de atuação que ela criou, está hoje perante uma clareza assustadora. A guerra parece 


\section{V.3 R.I fEV. 2015 - ARTIGOS}

ser o destino eterno da humanidade. Nenhuma compreensão da singularidade da situação contemporânea parece estar em condições de quebrar a força dessa tradição de atuação que impele para a guerra.

O desejo de aprofundar ainda mais a compreensão desse fato, levou Elias a escrever um outro livro denominado "Os Alemães". Nele traz uma contribuição para duas discussões afins: a questão das causas de genocídio e a questão da validade de sua teoria do processo civilizador. Elias sustentou que a ideia que os povos europeus têm de si mesmos como civilizados e superiores sempre supôs existência de outros povos não civilizados, que eram estigmatizados como inferiores. Entretanto, a constatação de que povos europeus podiam agir de maneira tão descivilizada contra seus próprios concidadãos, como os alemães tinham agido no holocausto, manteve-se assim, como a imagem central da maldade para a maioria das pessoas no ocidente.

Elias destacou as peculiaridades do processo de formação do Estado alemão e do habitus alemão:

1. A localização e as mudanças estruturais no povo que falou línguas germânicas e mais tarde alemão, em relação às sociedades vizinhas que falam outras línguas.

2. Papel desempenhado pelas lutas de eliminação entre grupos tribais.

3. A terceira peculiaridade estrutural do processo de formação do Estado alemão, que foi crucial no desenvolvimento do habitus alemão foi caracterizado por um processo de rupturas e de descontinuidades em que os modelos militares de comando e obediência prevaleceram em vários níveis sobre os modelos urbanos de negociação e persuasão.

Ao refletir sobre a relação entre Civilização e violência, sobre o monopólio estatal da violência física e sua transgressão, observa que a civilização a que se refere está completamente ameaçada. Corre perigo porque a salvaguarda dos padrões mais civilizados de comportamento e sentimento nas sociedades depende de condições específicas.

Uma dessas é o exercício da autodisciplina, relativamente estável em cada pessoa. Isso estaria vinculado a estruturas sociais específicas. Manutenção do habitual padrão de vida e pacificação social. É com esse aspecto de um processo 
civilizador, com a tensão entre pacificação e violência, que se preocupa. Assinala que quando se empenham em examinar o problema da violência física na vida social de seres humanos, as pessoas fazem frequentemente um tipo de pergunta errada: como é possível que tantas pessoas consigam viver normalmente juntas em paz, sem medo de ser atacadas ou mortas por pessoas mais fortes do que elas?

Seu enfoque diferente é uma questão de despertar um novo sentimento nas pessoas para o fato que é surpreendente, ímpar: o grau relativamente elevado de não violência que caracteriza as organizações sociais atuais. Só desse ponto de vista pode-se realmente explicar por que certas pessoas não se submetem a um código de civilização do nosso tempo.

Conforme Weber sublinhou, os Estados são caracterizados pelas pessoas que são seus governantes e que, em qualquer época, reivindicam para si mesmas o monopólio da força física. Mas a propriedade do monopólio estatal da força física é que ele pode servir às pessoas como uma arma perigosa. $O$ ponto crucial é o equilíbrio entre as duas funções do monopólio da violência: entre função para seus controladores, e em função para toda a população do Estado, no que se refere à pacificação interna.

A pacificação do Estado, a coação imposta por outros, foi transformada em autocoação. Somente quando as pessoas se tornam conscientes desse importante autoativado controle dos violentos impulsos espontâneos, em sociedades e Estados relativamente civilizados, é que o problema dos atos deliberados e premeditados de violência é trazido à luz adequada.

Nos negócios intraestatais, a violência entre pessoas e controlada e é punida. Nas relações interestatais vale o outro código: em todo Estado de grandes dimensões que está em constante preparação para a violência com outros Estados, quando tal violência é deflagrada, aqueles que a cometem são extremamente apreciados e em muitos casos louvados e recompensados.

Nas situações de crise da sociedade, os especialistas em violência autorizados pelo Estado - os representantes do monopólio estatal da força - podem acabar envolvidos numa luta violenta com grupos não autorizados pelo Estado.

$O$ desenvolvimento da Alemanha mostra aqui, em forma de paradigma, a reação de um establishment dominante e seus adeptos, diante de uma mudança na estrutura social que contribuiu para alterar uma proporção de poder que passava a Ihes ser desfavorável. A guerra perdida teve como efeito a redistribuição de forças 
que vinha ocorrendo silenciosamente sob a superfície do Estado imperial, estimulada pela rápida industrialização da Alemanha. Soldados e trabalhadores retiraram em massa sua obediência à liderança de uma classe derrotada. Os membros dos círculos que seguiam a tradição do velho establishment guilhermino sentiam-se "nacionais", uma vez que se consideravam fundamentalmente os verdadeiros representantes da nação, e todos os marginais, sobretudo os trabalhadores com suas organizações e os grupos minoritários, como os judeus alemães, eram vistos como não pertencentes nem a sua própria sociedade nem a nação alemã.

Se investigarmos as condições numa sociedade em que formas civilizadas de comportamento e de consciência começam a dissolver-se, veremos, uma vez mais, algumas das etapas desse movimento. É um processo de brutalização e desumanização que em sociedades relativamente civilizadas requer um tempo considerável. Em tais sociedades, terror e o horror dificilmente se manifestam sem um processo social bastante longo, durante o qual a consciência se decompõe. Os homens que, em fúria e desespero, participaram numa orgia de aniquilamento e destruição, tinham iniciado a arrancada com grandes esperanças. Entregaram-se à tarefa de destruir um mundo que Ihes negava qualquer significado e que, portanto, Ihes parecia ser ele próprio destituído de significação.

O que era valorizado como significativo perde completamente o sentido criando uma mesma motivação: o sentimento de estar encarcerado no sistema social que tornava muito difícil para gerações mais jovens encontrarem oportunidades para um futuro pleno de significado. Essa era na opinião de Elias a motivação central que originou os conflitos que levaram à Segunda Grande Guerra e que ainda permanecem ativos em diversos Estados nacionais quando da incapacidade de produção de sentido e valor para as gerações mais jovens.

Elias observa que há um pressuposto na sociedades industriais multipartidárias de hoje que impede a percepção desse problema. De acordo com esse pressuposto, a sociedades em questão encontram-se construídas de tal modo que toda e qualquer pessoa pode encontrar tarefas significativas e gratificantes na vida, desde que ele ou ela se esforcem ao máximo para consegui-la. Isso é falacioso, porque apenas reforça a ideia de que cabe ao indivíduo toda a possibilidade de sucesso ou fracasso na vida social.

Para Elias, esse processo é igualmente válido no que se refere a 
oportunidades não profissionais de uma vida significativa, incluindo sobretudo as oportunidades na esfera da luta política. Os conflitos políticos de hoje assumiram, sob muitos aspectos, as funções de criação de significado que, numa época anterior, eram desempenhadas pelas lutas religiosas.

Mas, diz Elias, é exatamente nessa direção que os jovens de hoje acham que o trabalho político dos partidos, tal como eles o vivenciam, fecha-lhes frequentemente a porta para qualquer atividade significativa. Muitos deles são suficientemente perspicazes e inteligentes para reconhecer com clareza os pontos vulneráveis e as deficiências das sociedades existentes. As pessoas de gerações mais antigas, com experiência nas lutas pelo poder, reconhecem com frequência a necessidade de compromissos. Os mais jovens são, na maioria das vezes, mais inflexíveis a respeito de meias-medidas. Coloca-se, então, um conflito de gerações: muitos dos mais argutos, os membros das jovens gerações não se satisfazem com soluções de compromisso, assim, quando desejam expressar e pôr em prática seus desejos políticos através dos canais institucionais da organização partidária, encontram o caminho obstruído, suas necessidades de significação bloqueadas. Trata-se de um conflito social de gerações em que os grupos estabelecidos aumentam sua pressão sobre os grupo mais jovens.

Nos anos 60 as pessoas mais jovens viram no movimento estudantil algo que já não encontravam no âmbito das instituições políticas estabelecidas, especialmente no espaço dos partidos solidamente organizados.

As atividades coletivas, a vida comunitária e as demonstrações de massa, todas elas proporcionam aos participantes não só um sentimento de solidariedade, mas também o sentimento de se possuir um propósito significativo, um sentimento de poder de uma mobilização feliz e prazerosa. Aí estavam os propósitos, aí estava o significado para os jovens.(ELIAS, 1997, p. 183)

Se a atuação extraparlamentar passou a ganhar mais sentido para as novas gerações, elas também não deixaram de criar espaços de atuação política alternativos, com sentidos diversos daqueles que mobilizaram as gerações mais velhas. Nesse processo também emergiu a própria figura da juventude, como um agente político e social que passa a mobilizar as reflexões de teóricos diante desta nova categoria social.

Assim, desde meados do século XX a juventude (ou as juventudes), como categoria social vai se construir dentro do processo civilizador mais amplo nas 
sociedades ocidentais, também pela expressão de um longo processo civilizador individual, através do qual as pessoas mais jovens nas sociedades industriais passam por um período de aprendizagem extenso e a duração invulgar do que passa a ser considerado período da juventude. É o que Elias identifica como uma juventude ampliada: a peculiaridade dessa extensa juventude e o problema de suas bases sociais talvez fiquem plenamente evidenciados quando se atenta para o fato de como essa reestruturação da vida humana é diferente das etapas anteriores do desenvolvimento social.

Aqui mais uma vez retorna-se ao problema: a violência que hoje atinge a juventude de modo particular está associada a dois aspectos enunciados por Elias: os processos de duplo vínculo em que o sentimento geral é de que se o Estado usa violência, nós também devemos usá-las. A violência engendra a contraviolência, a contraviolência aumenta a violência, e assim por diante. Por outro lado, o aspecto referente ao significado da vida para os mais jovens ganha outros contornos.

Elias enunciou esse aspecto em diferentes momentos de sua obra ao observar que foram explicitados de forma direta em "A Sociedade de Corte" e das implicações de se perceber também os elementos interdependentes de valores $\mathrm{e}$ significados nossos e deles:

Os objectivos que julgamos dignos do nosso esforço perseverante nunca
são determinados apenas pela satisfação pessoal nem pelo valor crescente
que julgamos passar a ter por avançarmos até ao fim do propósito que nos
indicávamos. São sempre determinados também pela nossa esperança de
ver que os outros tem consciência do nosso mérito, ou pelo aumento do
nosso prestígio pessoal. nenhum ser humano normalmente constituído
aceita a opinião que tem de si próprio e dos valores que preza se não a vê
confirmada na forma como é tratado pelos outros (Elias, 1987, p. 50).

Todas as posições privilegiadas dos indivíduos eram aos seus olhos e aos olhos daqueles com os quais conviviam VALOR, SIGNIFICADO E SENTIDO. Esses são termos fortes na obra de Elias, e nos ajudam a entender os conflitos presentes no mundo contemporâneo, afetando especialmente aos jovens e às crianças, que são, juntos com as mulheres e os idosos, os grupos mais vulneráveis em face do crescimento da violência - de forma especial aquela que vem sendo exercida pelos próprios agentes do Estado - pelas polícias e exércitos notadamente.

Como pudemos observar, os processos civilizadores estão eles próprios vinculados - também numa relação de interdependência com processos descivilizadores -, considerando as guerras e conflitos da atualidade, bem como as 


\section{V.3 R.I fEV. 2015 - ARTIGOS}

guerras não declaradas internas em que a população de jovens, crianças e mulheres de vários países da América Latina, África e Oriente Médio encontram-se na condição de maior vulnerabilidade.

No caso do Brasil, essa guerra interna tem uma fase que vem sendo ainda muito invisibilizada - suas maiores vítimas: jovens, homens, negros -, parece não tocar ao restante da sociedade. Os números de mortes violentas têm crescido ano a ano, valor que não tem se reduzido nem diante dos esforços de diminuição das desigualdades existentes no país. No último informe do Mapa da Violência - Os Jovens do Brasil, temos, numa série histórica, o seguinte resultado referente aos anos 1980 a 2012, segundo o Sistema de Informações de Mortalidade:

- 1.202.245 pessoas vítimas de homicídio

- 1.041 .335 vítimas de acidentes de transporte

- 216.211 suicidaram-se

- Total 2.459.791 vítimas.(Waiselfisz, 2014, p.26 ) ${ }^{3}$

- Considerando o longo período - 1980/2012 -, entre os jovens, $62,9 \%$ das mortes devem-se a causas externas. Na população não jovem, esse percentual representa só $8,1 \%$ das mortes acontecidas.

- Se na população não jovem só $2,0 \%$ dos óbitos foram causados por homicídio, entre os jovens os homicídios foram responsáveis por $28,8 \%$ das mortes acontecidas no período 1980 a 2012. (apud, p. 30) ${ }^{4}$

Para Waiselfisz, entre os fatores explicativos para a crescente violência com mortes afetando a jovens e em sua grande maioria negros e pobres - também estão relacionados os novos polos de crescimento econômico, em que cidades médias e pequenas passam a converter-se em centros migratórios, que, além de gerarem renda e emprego, atraem violência e criminalidade, para áreas que têm mecanismos precários de segurança pública. Trata-se também de formas de inserção precárias de uma nova população com poucos vínculos familiares e de solidariedade em um novo ambiente.

3 http://www.mapadaviolencia.org.br/pdf2014/Mapa2014 JovensBrasil Preliminar.pdf - acesso em 03/02/2015.

4 http://www.mapadaviolencia.org.br/pdf2014/Mapa2014 JovensBrasil Preliminar.pdf - acesso em 03/02/2015. 
Finalmente, o autor destaca um elemento que nos interessa aqui quando procura explicar as causas da violência em relação aos jovens, pobres e negros:

\begin{abstract}
um forte esquema de "naturalização" e aceitação social da violência que opera em vários níveis e mediante de diversos mecanismos, mas fundamentalmente pela visão que uma determinada dose de violência, que varia de acordo com a época, o grupo social e o local, deve ser aceito e torna- se até necessário, inclusive por aquelas pessoas e instituições que teriam a obrigação e responsabilidade de proteger a sociedade da violência. (WAISELFISZ, 2014, p.185)
\end{abstract}

O Brasil é ainda é um país muito dividido, lamentavelmente abrigando à condição de cidadão apenas aqueles que têm condições de se colocar no mercado como consumidores. Para aqueles que não têm esse estatuto, restam a violência e a morte. O lado frágil dos "descivilizados" tem mantido segura a consciência da sociedade dominante - na concepção de que são "eles" os "outros" os violentos "os pobres" - e nós - "os brancos, os educados, os civilizados" não temos nada a ver com isso. Diante desse quadro, Elias pode ainda nos auxiliar a entender como uma sociedade relativamente civilizada passa por um processo de brutalização e desumanização que requer um longo tempo para se estabelecer.

Podemos pensar com Elias na possibilidade de realizar uma biografia de uma nação, como ele realizou no caso da Alemanha? Que elementos teríamos como explicativos para entender as constituição do país como nação? Podemos ainda pensar, como observa Elias, que a relação entre Civilização e Violência pode adquirir alguns contornos específicos de longa duração como ele mesmo assinala? Ou seja: que elementos poderíamos destacar na formação de nossa sociedade que ainda permaneceriam vigentes?

Para tentar esboçar uma resposta a essa questão ${ }^{5}$, podemos buscar referência na obra de dois autores: Sérgio Buarque de Holanda e Gilberto Freyre. Do primeiro temos o livro "Raízes do Brasil" publicado em 1936. Nessa obra o autor busca analisar a formação da nação-Estado no Brasil, utilizando-se de alguns conceitos de Weber como o de "patrimonialismo" e "burocracia". No livro argumenta que a formação do Estado deu-se a partir do mundo rural, dominado pela figura do senhor. Essa formação criou um tipo humano específico que, longe do ethos guerreiro dos alemães, vai resistir ao trato impessoal da burocracia e do Estado. Nela "o homem cordial" se expressa pelos comportamentos afetivos, que se opõem

5 Para a finalidade desse ensaio as ideais que esboçamos são pontos iniciais que não poderão ser desenvolvidos em profundidade nesse trabalho. 
aos ritualismos e à polidez.

"O homem cordial" é visceralmente inadequado às relações impessoais que decorrem do posição e da função do indivíduo, e não da sua marca pessoal e familiar, das afinidades nascidas na intimidade dos grupos primários.(CANDIDO, A. in HOLANDA, 1995, p.17)

Dessa forma, é na figura deste tipo humano que temos a construção de um imaginário de cordialidade, de supressão de conflitos ou mesmo da intolerância a eles, criando a imagem de um país que se construiu sem grandes derramamentos de sangue, como em outros países. Essa imagem diz respeito a um aspecto cultural de nossa formação social. Outro, que também está relacionado com nossas origens, podemos vislumbrar no obra de Gilberto Freyre - Casa Grande \& Senzala (1933). Nela o autor trata de aspectos da formação social brasileira, também de um ponto de vista cultural, já que destaca elementos do cotidiano, da religiosidade, hábitos alimentares, enfermidades, práticas sexuais da vida na Casa Grande e nas Senzalas, fruto da relação entre senhores e escravos durante os anos de formação da sociedade brasileira, marcando a presença e influência africana. Cria a imagem de uma relação "adocicada" pela economia da cana-de-açúcar, a relação racial entre brancos e negros escravos. Essa imagem, já muito criticada, não deixa, no entanto, de expressar as dificuldade e limitações de trato nos conflitos. Esse aspecto foi notado por Elias quando observa justamente que a possibilidade de regimes políticos parlamentares multipartidários legitima dos conflitos.

Os conflitos não são relegados para a categoria do extraordinário, anormal
ou irracional mas, pelo contrário, são tratados como aspectos normais e
indispensáveis à vida social. A esse respeito, poder-se-ia dizer que a
democracia contradiz as leis da racionalidade clássica, a qual iguala ordem
com harmonia, ou seja, ausência de conflito.[..] A disputa é limitada às
formas não-violentas de luta travada, em primeiro lugar, na forma de
discussão ou duelo verbal, cuja resolução depende de todos os
participantes aderirem a certas regras. (ELIAS, 1997, p. 262).

Com isso, Elias destaca que os conflitos podem e dever ser assumidos pela sociedade e devem existir canais reconhecidos e legitimados para operar com eles e tentar superar as diferenças entre os grupos. Essa situação nos remete a outra obra de Elias, muito esclarecedora desse processo - da própria relação de interdependência entre - Estabelecidos e Outsiders. Quando nos defrontamos com a violência presente em nossa sociedade, somos obrigados a olhar para todos os elementos que a constituem e certamente um desses elementos tem sido a forma duradoura como a desigualdade social tem operado no Brasil, criando a ideia 
mesmo da existência de seres humanos superiores e seres humanos inferiores (que são os pobres e negros em sua grande maioria). Nesse quadro, tanto o componente social e econômico quanto o racial concorrem para criar um certo ambiente de indiferença. Elias nos provoca, num certo sentido, ao inverter a questão da guerra e da violência, justamente ao colocá-la em outros termos: como é possível tantos bilhões de seres humanos viverem ainda juntos sem tantos conflitos? Com Elias ainda concluímos:

Nenhuma pacificação é possível enquanto a distribuição de riqueza for muito desigual e as proporções de poder demasiado divergentes. E, viceversa, nenhuma prosperidade a longo prazo é possível sem um pacificação estável". (ELIAS, 1997, p. 401).

Se as instâncias de autocontrole interno e de controle externo seguem com relativa eficácia, não podemos ignorar as instâncias estabelecidas de poder, que têm atuado na própria definição dos valores, do sentido e do significado dominante. $\mathrm{O}$ que nos faz olhar para a busca da paz - de uma paz duradoura que possa de fato um dia se tornar realidade.

\section{REFERÊNCIAS}

BOBBIO, Norberto. Teoria Geral da Política: a filosofia política e as lições dos clássicos. Editora Campus : Rio de Janeiro, 2000.

ELIAS, Norbert. A Sociedade de Corte: Lisboa, Editorial Estampa Ltda,1987.

A Condição Humana. Lisboa : Difusão Editorial Lda. - Rio de Janeiro, Editora Bertand Brasil, S.A., 1985.

. O Processo Civilizador: uma História dos Costumes. Rio de Janeiro, Jorge Zahar Editores, 1990, vol.1.

. O Processo Civilizador: Formação do Estado e Civilização. Rio de Janeiro, Jorge Zahar Editores, 1993, vol. 2.

A Sociedade dos Indivíduos. Rio de Janeiro, Jorge Zahar Editores, 1994.

. Os Alemães - A luta pelo poder e a evolução do habitus nos séculos XIX e XX. Rio de Janeiro, Jorge Zahar Editores, 1997.

ELIAS, Norbert; SCOTSON, John L. Os Estabelecidos e os Outsiders. Rio de Janeiro, Jorge Zahar Editores, 1999.

FREYRE, Gilberto. Casa Grande \& Senzala. Rio de Janeiro : Record, 1999. 
HOLANDA, Sérgio B. Raízes do Brasil. São Paulo : Companhia das Letras, 1995. MANIN, Bernard. Paz. Enciclopédia EINAUDI, v. 5. 273-295, Imprensa Nacional Casa da Moeda : Lisboa, 1985.

WAISELFISZ, Julio. Mapa da Violência - Os Jovens do Brasil. Rio de Janeiro : FLACSO Brasil, 2014. 